\title{
Matching prevalence of peripheral arthritis and acute anterior uveitis in individuals with ankylosing spondylitis
}

\author{
Walter P Maksymowych, Chung-Tei Chou, Anthony S Russell
}

\begin{abstract}
Objective-To study the association between the occurrence of peripheral arthritis and of acute anterior uveitis during the course of ankylosing spondylitis (AS). Methods-Retrospective clinical follow up by both chart review and direct patient interview was performed on 271 individuals comprised of 222 local white and 49 Taiwanese individuals with AS.

Results-Of 89 white patients with acute anterior uveitis, $36(40.4 \%)$ also had peripheral arthritis, compared with only $33(24 \cdot 8 \%)$ having peripheral arthritis among the 133 who did not have acute anterior uveitis $(p<0.02)$. Thirty seven $(78.7 \%)$ of 49 Taiwanese individuals with AS had peripheral arthritis and these included all 10 patients with acute anterior uveitis from the entire disease cohort $(\mathrm{p}<0.05)$.

Conclusions-This cross-sectional survey of AS patients supports the view that patients who develop peripheral arthritis are also more likely to develop acute anterior uveitis.
\end{abstract}

(Ann Rheum Dis 1995; 54: 128-130)

The prevalence of peripheral arthritis in ankylosing spondylitis (AS) varied from 30 to $50 \%$ in different studies, ${ }^{12}$ whilst the prevalence of acute anterior uveitis varied from 25 to $40 \%{ }^{3}{ }^{4}$ Such extraspinal complications may predate the onset of ankylosing spondylitis and although acute anterior uveitis may occur at any time during the disease course, peripheral synovitis occurs most frequently with, or shortly after, the onset of axial symptoms. ${ }^{5}$

It is clear that there is no temporal relationship between the occurrence of peripheral arthritis and acute anterior uveitis in individuals with $\mathrm{AS}$, but to our knowledge there have been no reports describing an association between the occurrence of peripheral arthritis and that of acute anterior uveitis during the course of a particular individual's disease. We have collected an extensive clinical database relating to more than 250 individuals from two ethnically and geographically distinct populations of individuals with AS and an average duration of follow up of 18 years, and examined the coprevalence of peripheral arthritis and acute anterior uveitis.

\section{Patients and methods}

PATIENT POPULATION

The patient population comprised 222 unrelated white individuals with AS as defined by the modified New York criteria. ${ }^{6}$ These included inpatients in addition to outpatients referred to rheumatologists, community and university affiliated, in the City of Edmonton. Referrals to all rheumatologists in this city are made by family physicians with no overt selection bias. There were 167 males and 55 females of average age 42.4 years (range 21-77) and average age at onset of disease (AS) of 24.5 years (range $12-58$ ). Of these, 18 had associated psoriasis and 19 had inflammatory bowel disease. Eleven patients described an age of onset of disease (AS) greater than 40 years; of these, two had associated psoriasis and two had Crohn's disease.

A second population of AS patients included 49 unrelated Chinese individuals from Taiwan. These included both inpatients and outpatients referred to a specialist in rheumatology. This population included 44 males and five females of average age 37.4 years (range 16-61) and average age at onset of disease (AS) 18.6 years (range $12-28$ ).

Clinical data on each patient were compiled by direct patient interview and by chart review. Peripheral arthritis was defined as synovitis, documented by a rheumatologist, occurring in joints outside the axial skeleton excluding the adjacent joints, the shoulders, and hips. Patients were noted to have had acute anterior uveitis when this was documented by an ophthalmologist.

\section{HLA TYPING}

HLA-B27 typing was performed using standard microcytotoxicity assays and typing serum. When serological typing was not available (for example over weekends), molecular typing for HLA-B27 was performed as described previously (67 samples). ${ }^{7}$

\section{STATISTICS}

Comparison of patient subgroups was performed using the $\chi^{2}$ and Fisher's exact tests. Odds ratios were determined according to 
Woolf's formula ${ }^{8}$ and Haldane's modification of Woolf's formula. ${ }^{9}$

\section{Results}

No sex difference in the prevalence of extraspinal complications was noted.

Sixty nine patients $(31 \cdot 1 \%)$ had experienced at least one episode of peripheral arthritis. These included 53 males and 16 females of average age 42.6 years (range 24-72) and average age at onset of disease (AS) of $25 \cdot 4$ years (range 12-54). Eighty nine patients $(40 \cdot 1 \%)$ had had at least one episode of acute anterior uveitis. These included 68 males and 21 females of average age 41.3 years (range 23-72) and average age at onset of disease (AS) of 22.9 years (range 12-54). Both peripheral arthritis and acute anterior uveitis were noted at some time during the disease course in 36 $(16 \cdot 2 \%)$ patients with AS. Thus of the 89 patients with acute anterior uveitis, 36 also had peripheral arthritis $(40.4 \%)$, compared with only 33 of the 133 patients who did not have acute anterior uveitis $(24.8 \%)(p<0.02)$.

The average age of individuals who developed both extraspinal complications was $44 \cdot 1$ years (range $25-72$ ) and the average age at onset of disease (AS) was $25 \cdot 7$ years (range 12-54). The average age of the 100 AS individuals without extraspinal complications was 40.3 years (range 21-77) and average age at onset of disease (AS) was 25.0 years (range 12-58). Among AS individuals with associated psoriasis, inflammatory bowel disease, or both, nine of 14 individuals with acute anterior uveitis had also experienced peripheral arthritis $(64.3 \%)$, compared with 10 of 22 individuals without acute anterior uveitis $(45.4 \%$ ) (not statistically significant: $\mathrm{p}>0 \cdot 05$ ).

Twenty-one AS patients were noted to be HLA-B27 negative; the only three B27 negative patients who had had acute anterior uveitis had also experienced peripheral arthritis. One of these three had associated psoriasis and one had Crohn's disease.

Clinical data were also available on 49 individuals Chinese ethnic origin. Thirty seven $(78 \cdot 7 \%)$ Chinese individuals with AS had had at least one episode of peripheral arthritis and $10(21.3 \%)$ had had at least one episode of acute anterior uveitis. All 10 patients with acute anterior uveitis had also experienced peripheral arthritis $(p<0.05$, one tail test; $\mathrm{p}>0.05$, two tail test). The table summarises

Ankylosing spondylitis patient subgroups according to disease phenotype

\begin{tabular}{lllr}
\hline & $\begin{array}{l}\text { Peripheral } \\
\text { arthritis }+\end{array}$ & $\begin{array}{l}\text { Peripheral } \\
\text { arthritis - }\end{array}$ & Total \\
\hline White patients & 36 & 53 & 89 \\
AAU + & 36 & $\frac{100}{153}$ & $\frac{133}{222}$ \\
AAU - & $\frac{33}{69}$ &
\end{tabular}

Odds ratio $=2 \cdot 1 ; 95 \%$ confidence intervals $1 \cdot 7$ to 3.6

Chinese patients

$\begin{array}{lrrr}\text { Chinese patients } & & 0 & 10 \\ \text { AAU + } & 10 & \frac{12}{12} & \frac{39}{49} \\ \text { AAU - } & \frac{27}{37} & 19\end{array}$

Odds ratio $=9 \cdot 5 ; 95 \%$ confidence intervals $0 \cdot 816$ to infinity

$\mathrm{AAU}=$ Acute anterior uveitis. the subgrouping of both white and Chinese patients according to their disease phenotype.

\section{Discussion}

This analysis of two geographically and ethnically distinct populations of individuals with AS demonstrates a significant association between the prevalence of peripheral arthritis and acute anterior uveitis in AS and, we believe, represents a novel clinical observation.

Since there is a difference of $3 \cdot 1$ years in the average duration of disease (AS) between individuals with both extraspinal complications (18.4 years) and those with axial disease alone (15.3 years), it could be argued that this observation is secondary to age as a confounding variable. However, peripheral arthritis is often established shortly after the onset of axial symptoms, ${ }^{5}$ whilst acute anterior uveitis can occur at any time. It can therefore also be argued that with increasing duration of follow-up the association noted in this study could become even more prominent. The high prevalence of peripheral arthritis in Chinese individuals with AS has been noted previously ${ }^{10}$ and it is of interest that this AS subgroup also included all 10 patients with acute anterior uveitis.

The association between the two extraspinal complications may be indirect and could, for example, reflect an association between disease severity and peripheral arthritis or acute anterior uveitis, or both. As this study represents a cross-sectional survey of patients referred to a rheumatologist, there may be a selection bias for more severely affected patients to be referred, and to be more closely followed. However, even though this may account for a greater prevalence of acute anterior uveitis or peripheral arthritis than in a community sampling, there is no a priori reason why these complications should occur in association in the same AS patient. This issue is clearly difficult to resolve in a referred, clinic population.

There are several possible explanations for our observation. Both tissues have in common potential autoantigenic epitopes (for example type II collagen), which may cross react with extrinsic, possibly bacterial, antigens. Bacterial antigens and cell mediated immune reactivity to bacterial antigens have been demonstrated in peripheral joint tissues. ${ }^{11}$ This association could therefore reflect a significant abnormality in mucosal permeability in the small intestine. Ileocolonoscopic studies have revealed that inflammatory changes in the terminal ileum are common in patients with AS complicated by peripheral arthritis, but occur only occasionally in those with pure axial disease. ${ }^{12}$ The association may represent a genetic predisposition, and, although there are no reports of familial segregation of extraspinal complications, family data have implicated polymorphism in an additional genetic factor in predisposition to acute anterior uveitis in HLA-B27 positive individuals with AS. ${ }^{13}{ }^{14}$ Recent work from our laboratory has also implicated an HLA-linked proteasome gene 
(LMP2), thought to be involved in class I associated antigen processing, in extraspinal complications of AS. This association could therefore reflect qualitative or quantitative differences, or both, in antigen processing of an autoantigenic epitope common to peripheral joint and anterior uvea.

In conclusion, our data suggest that AS patients who have developed peripheral arthritis are also more likely to have developed acute anterior uveitis.

This work was supported by an establishment grant from the Alberta Heritage Foundation for Medical Research and an operating grant from the Medical Research Council of Canada. We thank Connie Chorney for preparing the manuscript.

1 Cruickshank B. Pathology of ankylosing spondylitis. Clin Orthop 1971; 74: 43-58.

2 Resnick D. Patterns of peripheral joint disease in ankylosing spondylitis. Radiology 1974; 110: 523-32.

3 Rosenbaum J T. Characterization of uveitis associated with spondyloarthritis. $₹$ Rheumatol 1987; 16: 792-6.

4 Edmunds L, Elswood J, Calin A. New light on uveitis in ankylosing spondylitis. $\mathcal{F}$ Rheumatol 1991; 18: 50-2.

5 Ogryzlo M A, Rosen P S. Ankylosing (Marie-Strumpell) spondylitis. Postgrad Med $\mathcal{f} 1969 ; 45: 182-8$
6 Van der Linden S, Valkenburg H A, Cats A. Evaluation of diagnostic criteria for ankylosing spondylitis: a proposal for modification of the New York criteria. Arthritis Rheum 1984; 27: 361-8.

7 Dominguez O, Coto E, Martinez-Naves E, Chao S Y, Lopez-Larrea C. Molecular typing of HLA-B27 alleles. Immunogenetics 1992; 36: 277-82.

8 Woolf B. On estimating the relation between blood group and disease. Ann Hum Genet 1955; 19: 251-3.

9 Haldane J B S. The estimation and significance of the logarithm of a ratio of frequencies. Ann Hum Genet 1956; 20: 309-11.

10 Khan M A. Spondyloarthropathies in non-Caucasian populations of the world. In: Ziff $M$, Cohen S B, eds. The spondyloarthropathies, advances in inflammation research. New York: Raven Press, 1985; 91-9.

11 Granfors K. Do bacterial antigens cause reactive arthritis? In: Khan M A, ed. The spondyloarthropathies, rheumatic disease clinics of North America, vol. 18. Philadelphia: W B Saunders Co., 1992; 37-48.

12 Mielants H, Veys E M, Cuvelier C, De Vos M, Botelberghe L. HLA-B27 related arthritis and bowel inflammation. II. Ileocolonoscopy and bowel histology in patients with HLA-B27 related arthritis. $\mathcal{f}$ Rheumatol 1985; 12: 294-8.

13 Van der Linden S M, Rentsch H V, Gerber N, Cats A Valkenburg H A. The association between ankylosing spondylitis, acute anterior uveitis, and HLA-B27: the spondylitis, acute anterior uveitis, and HLA-B27: the
results of a Swiss family study. $B r f$ Rheumatol 1988; 27: results of

14 Derhaag P J F M, Linssen A, Broekema N, de Waal L P, Feltkamp T E W. A familial study of the inheritance of HLA-B27 positive acute anterior uveitis. Am $\mathcal{F}$ Ophthalmol 1988; 105:603-14. 